\title{
Gerbang Tertutup dan Terbuka pada Handphone Android Menggunakan Bluetooth
}

\author{
Sri Mulyati ${ }^{l}$; Sumardi Sadi ${ }^{2}$ \\ ${ }^{1}$ Program Studi Teknik Informatika \\ ${ }^{2}$ Program Studi Teknik Elektro \\ Fakultas Teknik - Universitas Muhammadiyah Tangerang \\ Jl. Perintis Kemerdekaan I/33, Cikokol Kota Tangerang \\ ${ }^{1}$ sri.mulyati@umt.ac.id \\ ${ }^{2}$ sumardiumt@umt.ac.id
}

\begin{abstract}
The problem with opening the gate opening now is to work manually, which is opening and closing as well secure with a key, then pull or push the gate. This is certainly less efficient and less effective because it requires time and energy to do it. One solution is to make a control device it works automatically ie using a microcontroller, Bluetooth, and servo motor, with communication devices, Android-based handphones. Laboratory experimental methods have been carried out to make 'open and close tools the gate with a cellphone'. Based on the results of the trial using Bluetooth and mobile phones, this tool can work up to a distance of 11.5 meters with a response time of 1 second. This prototype tool is very cheap, practical, efficient and effective in opening and closing gates. Not all Bluetooth can open and close gates because the password is required for the accent. This prototype is a simulation tool that works well.
\end{abstract}

Keywords: Gate, microcontroller, bluetooth, smartphone, android

\begin{abstract}
ABSTRAK
Masalah dengan membuka pintu gerbang sekarang adalah bekerja secara manual, yang membuka dan menutup juga aman dengan kunci, lalu tarik atau dorong gerbang. Ini tentu saja kurang efisien dan kurang efektif karena memerlukan waktu dan energi untuk melakukannya. Salah satu solusinya adalah membuat perangkat kontrol yang berfungsi secara otomatis yaitu menggunakan mikrokontroler, Bluetooth, dan motor servo, dengan perangkat komunikasi, ponsel berbasis Android. Metode eksperimental laboratorium telah dilakukan untuk membuat 'membuka dan menutup alat gerbang dengan ponsel'. Berdasarkan hasil uji coba menggunakan Bluetooth dan ponsel, alat ini dapat bekerja hingga jarak 11,5 meter dengan waktu respons 1 detik. Alat prototipe ini sangat murah, praktis, efisien dan efektif dalam membuka dan menutup gerbang. Tidak semua Bluetooth dapat membuka dan menutup gerbang karena kata sandi diperlukan untuk aksen. Prototipe ini adalah alat simulasi yang berfungsi dengan baik.
\end{abstract}

Kata kunci: Gate, microcontroller, bluetooth, smartphone, android 


\section{PENDAHULUAN}

Permasalahan yang ada saat ini adalah pada saat membuka dan menutup gerbang terutama gerbang gerbang yang berukuran besar masih terdapat kesulitan, karena pada umumnya dilakukan dengan cara mendorong atau menarik untuk membuka dan menutupnya. Hal ini dapat dijumpai terutama di industri industri, baik industri kecil atau industri besar. Bahkan buka tutup pintu gerbang pada perumahan penduduk pun dilakukan dengan cara yang sama yaitu buka tutup secara manual. Sebagai solusi dari permasalah ini adalah menggunakan alat kendali dari jarak jauh menggunakan bluetooth yang ada pada handphone. Dengan demikian tidak lagi mengeluarkan tenaga untuk buka tutup gerbang, tentunya ini akan mengehemat energi, efisen dan sangat efektif, dan pintu gerbang pun akan awet karena bekerja secara otomatis. Hal ini dapat direalisasikan berkat perkembangan sitem mikrokontroler dan Programmable Logic Controller (PLC). Peranan sistem kontrol berbasis mikrokontroller ini sangat luas pemakaiannya. Beberapa contoh sistem kontrol berbasis mikrokontroller telah dilakukan sumardi [1-14].

Tujuan dari penelitian ini : penggunaan mengirim kata sandi yang digunakan untuk membuka atau mengunci pintu melalui aplikasi terminal bluetooth yang akan mengirimkan data ke modul bluetooth pada sistem. Sistem menerima kata sandi yang dikirimkan oleh pengguna dan menerjemahkannya menjadi gerakan membuka atau mengunci pintu pada servo, dimana Servo membuka atau mengunci pintu sesuai dengan perintah yang sebelumnya dimasukkan.

\section{KAJIAN LITERATUR}

\section{Komponen Komponen Utama}

\section{a. Arduino Uno}

Arduino uno adalah suatu modul yang terdiri dari bagian input, output, mode minimum mikrokontroler. Arduino uno ini berfungsi untuk menyimpan program dan memproses program. Dengan eksekusi dari input dan responnya keluar melalui bagian output.

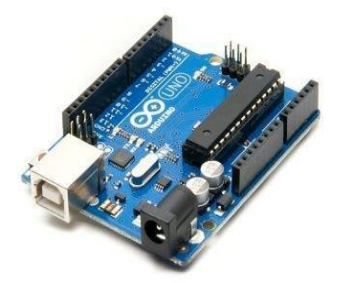

Gambar 1. Arduino Uno

\section{b. Liquid Criystal Display (LCD)}

LCD ini berfungsi untuk menampilkan hasil proses program yang di eksekusi. LCD ini memiliki 2 X 16 bit karakter.

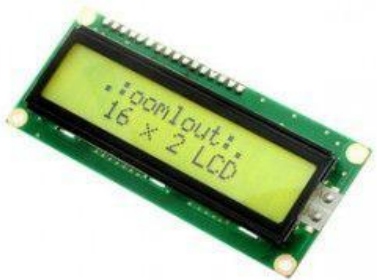

Gambar 2. LCD 


\section{c. Bluetoot HC-05}

Bluetooth ini berfungsi sebagai alat kendali pada bagian input mikrokontroler yang akan terkoneksi dengan android yang ada dalam smartphone.

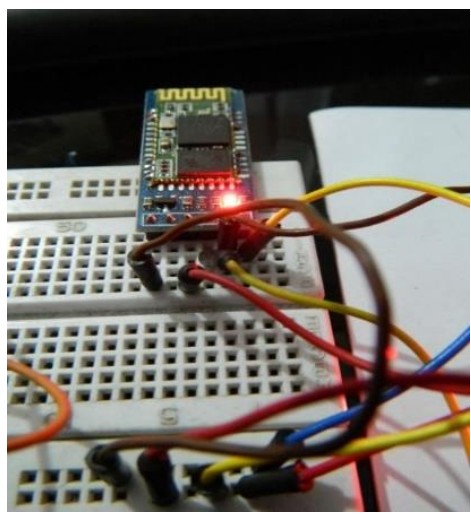

Gambar 3. HC-05

\section{d. Servo}

Motor servo sebagai alat penggerak yang dipasang pada bagian output mikrokontroler.

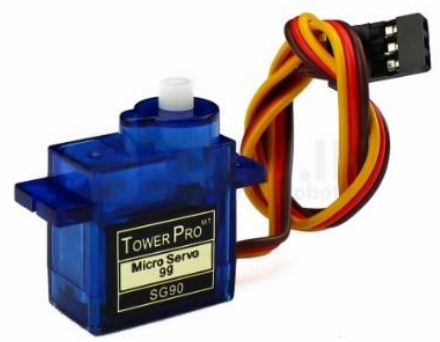

Gambar 4. Servo

\section{e. Potensiometer $10 \mathrm{~K}$}

Potensiometer merupakan alat untuk mengatur arus yang akan mengendali program pada bagian input.

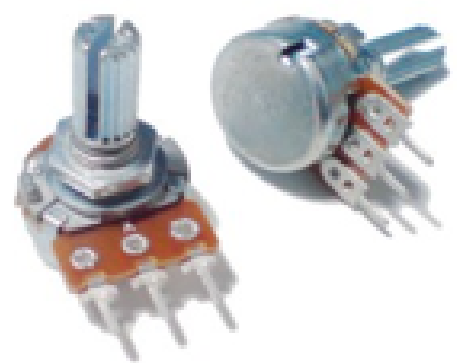

Gambar 5. Potensiometer $10 \mathrm{~K}$ 


\section{METODELOGI}

\section{a. Blok Diagram}

Blok diagram

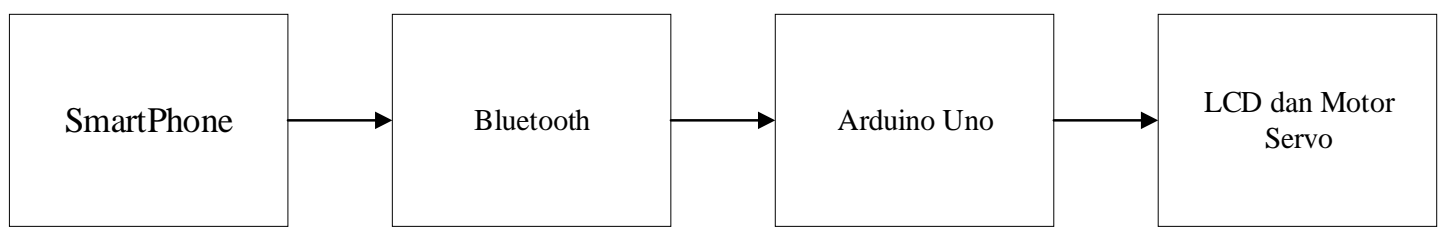

Gambar 6. Blok diagram

\section{b. Diagram Sistem}

Berikut adalah gambar diagram system berupa flowchart.

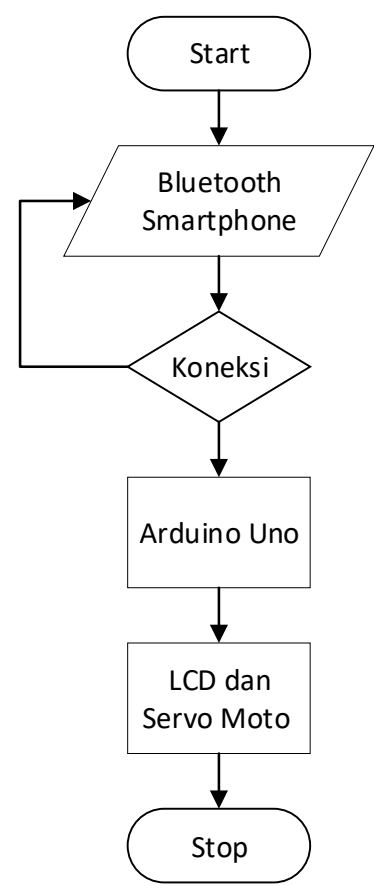

Gambar 7. flowchart.

\section{c. Alat dan Bahan}

Bahan dan alat yang digunakan dalam penelitian ini secara umum sebagai berikut :

1. 1 buah Arduino Uno (Arduino sebagai IDE)

2. 1 buah Modul Bluetooth HC-05

3. 1 buah Motor Srvo

4. 1 buah LCD $16 \times 2$

5. 1 buah potensiometer $10 \mathrm{~K}$

6. Handphone (Sebagai control aplikasi bluetoot)

7. Laptop

8. Software Arduino IDE

9. Kabel jumper secukupya

10. $\mathrm{PCB}$

11. Project board (sebagai media tes komponen) 


\section{d. Langkah langkah perancangan sistem}

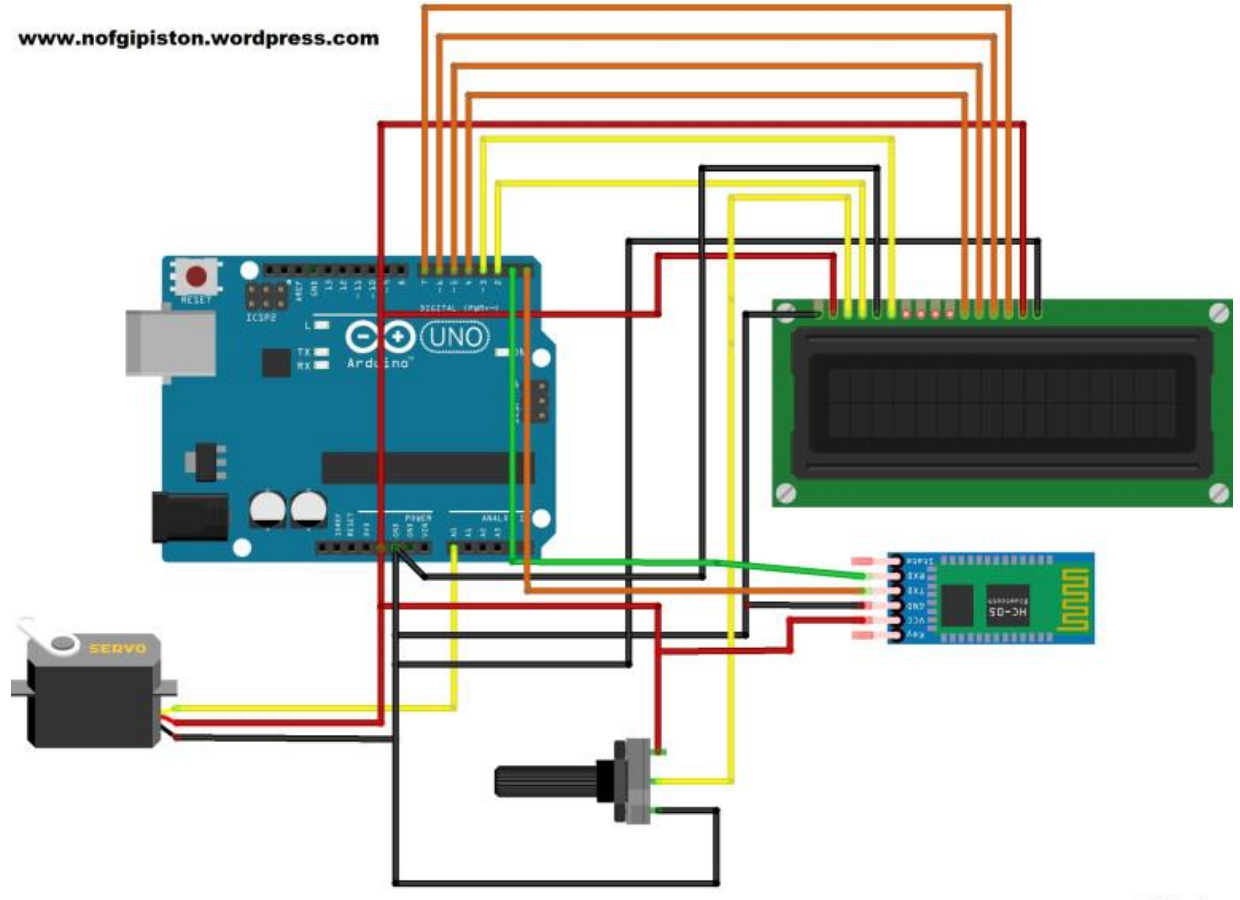

Gambar 8. Wiring Diagram

e. Gambar disain hardware

f. Cara kerja

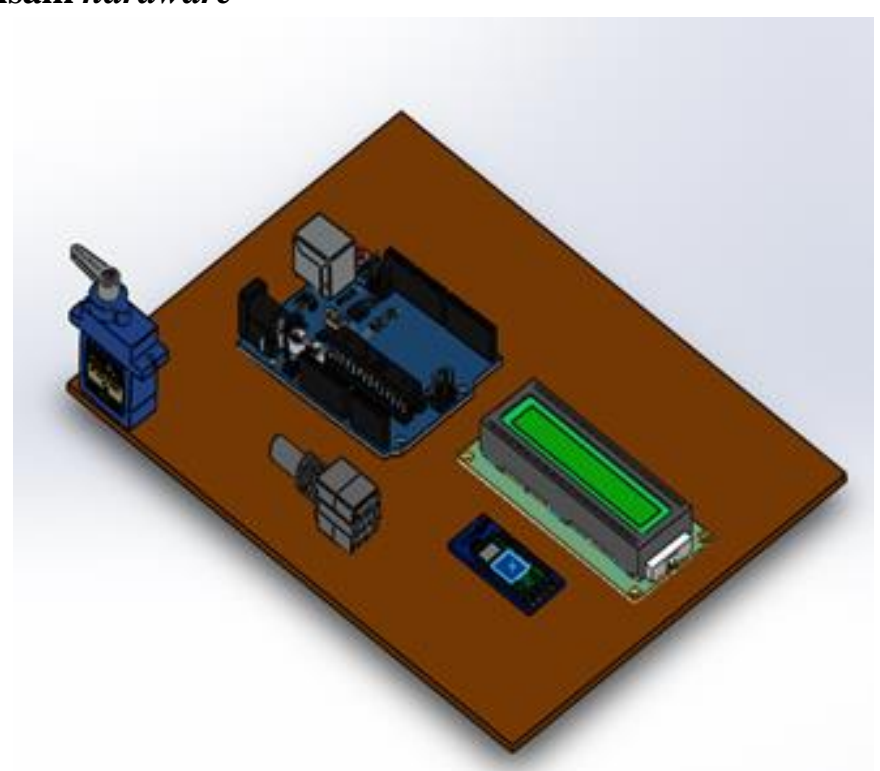

Gambar 9. Disain hardware

1. Buka program ARDUINO yg telah di buat, kemudian UNDUH pada alat yg kita buat, tunggu beberapa menit sampi unduhan selesai.

2. setelah LCD nyala, buka aplikasi ARDUINOT BLUETOOT HC-05 yang telah di download di hp.

3. Koneksikan dengan alat dengan caeara mentari bluetooth HC-05.

4. Pilih tombol reset terlebih dahulu pada tampilan push button yang tersedia. 
5. Lalu mulia coba buka tutup pintu dengan menekan buka maka pintu terbuka dan jika tekan tutup maka pintu ter tutup.

\section{HASIL DAN PEMBAHASAN}

Hasil penelitian diperoleh dari data pengujian dari blok diagram sistem secara menyeluruh.

1. Pengujian koneksi bluetooth

Pengujian koneksi bluetooth dilakukan untuk mengetahui jarak transmisi antara bluetooth yang terdapat pada smartphone android dengan bluetooth HC-05 yang sudah terintegrasi dengan board arduino uno. Pengujian koneksi bluetooth diperlihatkan pada tabel 1.

\begin{tabular}{lc}
\hline \multicolumn{1}{c}{ Jarak Antara Sistem Bluetooth } & \multicolumn{1}{c}{ Keterangan } \\
\hline 1 meter & Lancar menerima perintah \\
1,5 meter & Lancar menerima perintah \\
2 meter & Lancar menerima perintah \\
2,5 meter & Lancar menerima perintah \\
3 meter & Lancar menerima perintah \\
3,5 meter & Lancar menerima perintah \\
4 meter & Lancar menerima perintah \\
4,5 meter & Lancar menerima perintah \\
5 meter & Lancar menerima perintah \\
5,5 meter & Lancar menerima perintah \\
6 meter & Lancar menerima perintah \\
6,5 meter & Lancar menerima perintah \\
7 meter & Lancar menerima perintah \\
7,5 meter & Lancar menerima perintah \\
8 meter & Lancar menerima perintah \\
8,5 meter & Lancar menerima perintah \\
9 meter & Lancar menerima perintah \\
9,5 meter & Lancar menerima perintah \\
10 meter & Lancar menerima perintah \\
10.5 meter & Lancar menerima perintah \\
11 meter & Lancar menerima perintah \\
11,5 meter & Koneksi Terputus \\
\hline
\end{tabular}

Gambar 10. Tabel uji coba 


\section{Tampilan ketika buka aplikasi bluetooth}

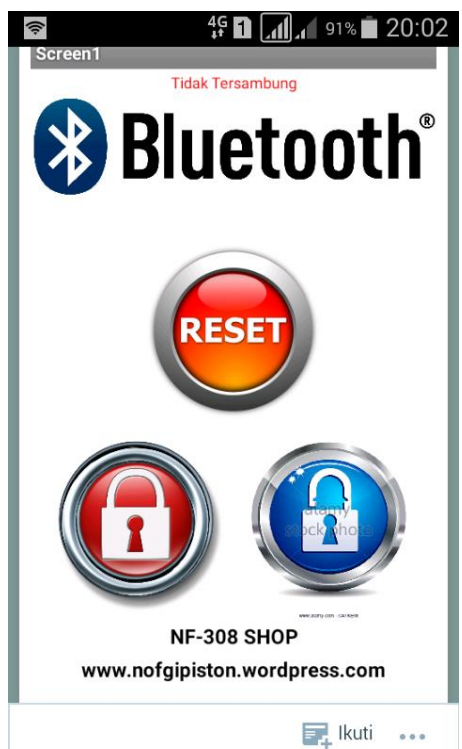

Gambar 11. Tampilan menu aplikasi

3. Koneksi aplikasi dengan alat

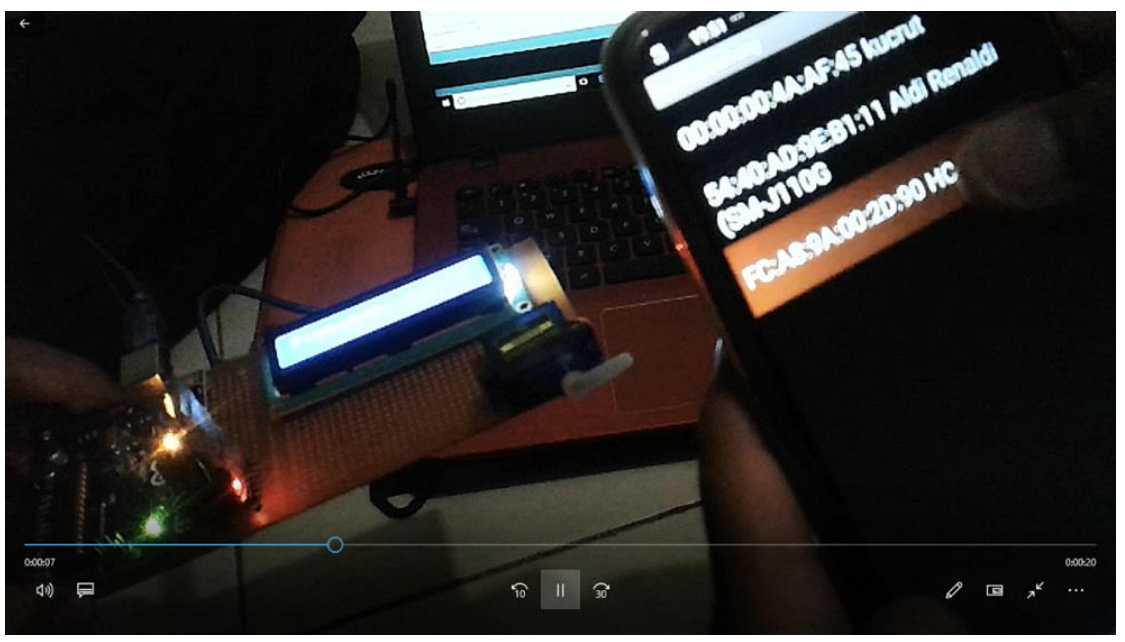

Gambar 12. Koneksi HP dengan alat

cara membuka aplikasi terlebih dahulu kemudian klik tulisan bluetooth, kemudian tampil seperti yang di gambar pilih FC:AS;9A;00;20;90 HC. 


\section{Keadaan menutup}

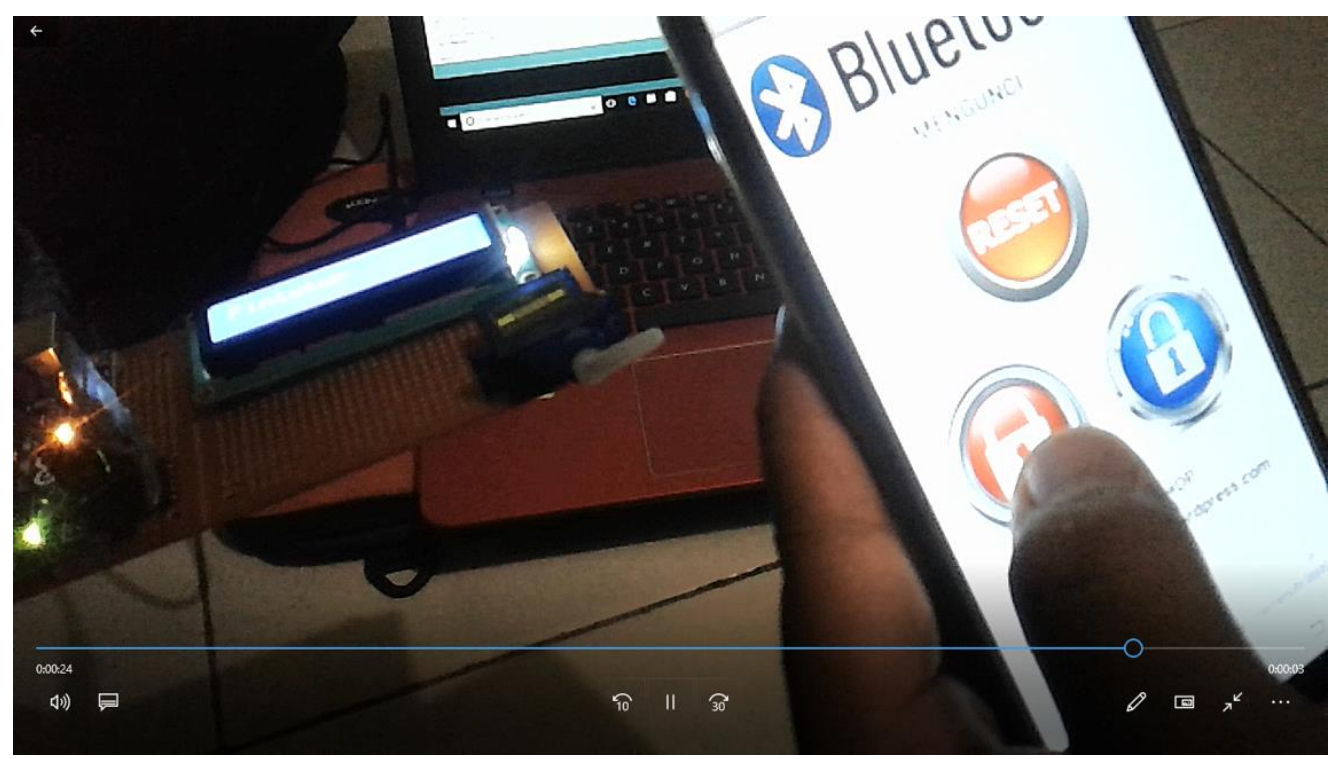

Gambar 13. Koneksi untuk menutup

(kelik tombol menu yang bergambar gembok tertutup dan berwarna merah)

\section{Keadaan membuka}

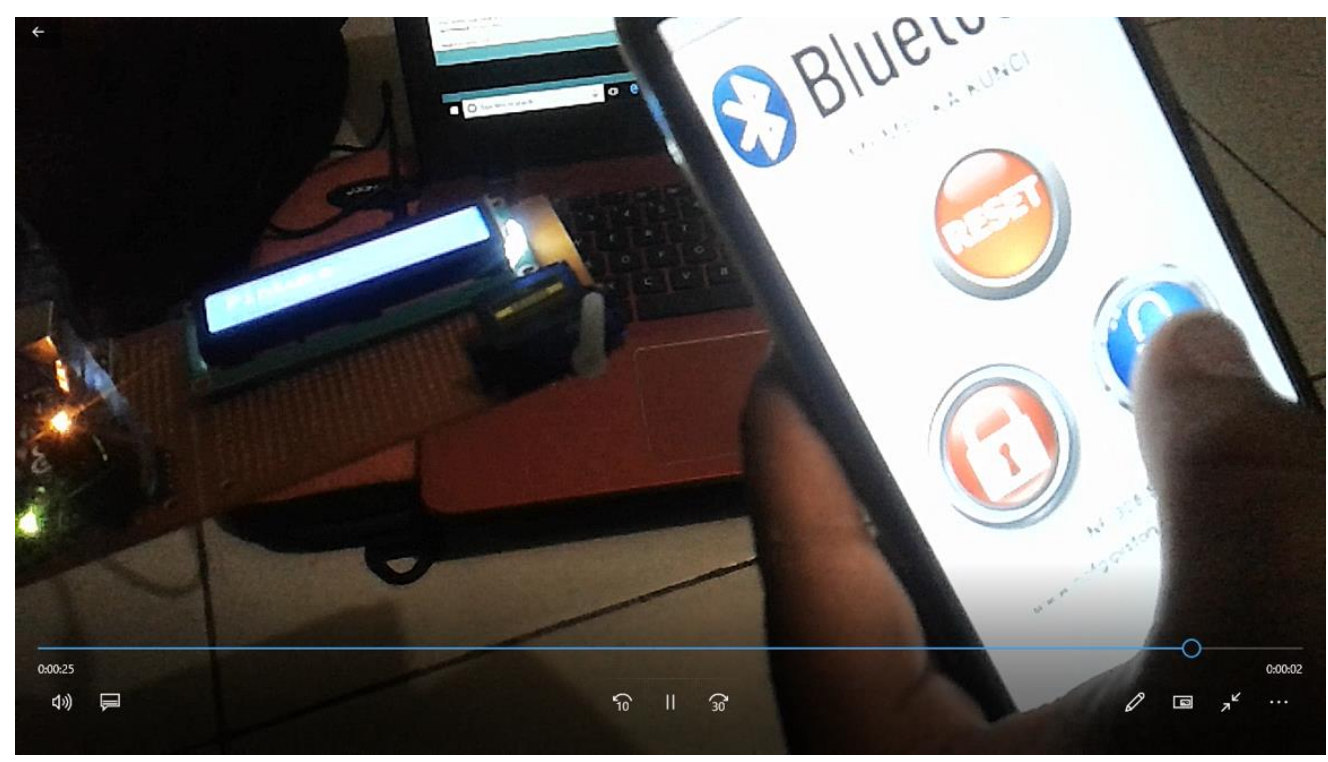

Gambar 14. Koneksi untuk membuka

(klik tombol yang bergambar buka kunci gembok dengan warna biru) 


\section{KESIMPULAN}

Prototipe alat kendali buka tutup pintu gerbang dapat bekerja dengan baik, sangat efektif dan efisien, serta dapat dibuat dengan biaya yang sangat murah. Alat ini merupakan solusi yang bekerja secara otomatis dengan menggunakan bluetooh, dan smartphone. Berdasarkan pengujian yang telah dilakukan, alat ini dapat menerima perintah untuk membuka atau menutup pintu dari aplikasi smartphone android dengan waktu respons 1 detik dengan jangkauan jarak hingga 11,5 meter.

\section{DAFTAR PUSTAKA}

[1] S. Sadi, S. Mulyati, and D. A. Kurniawan, "Items' Filling System Prototype with Sorting System According to the Color and Height of the Conveyors based on PLC Omron CPE1E," Int. Res. J. Eng. Technol., vol. 869, 2008.

[2] S. Sadi, "Room Temperature Control System Prototype Industry Based Programmable Logic Controller Zelio SR2 B121 BD," vol. 6, no. 4, pp. 52-69, 2015.

[3] S. Mulyati, Z. Mubarok, E. Engineering, S. Program, and I. S. Program, "DESIGN OF SEPARATION METAL AND NON-METAL GOODS BASED ON CP1E-E30SDR-A AND PNEUMATIC Page No : 1296," vol. IX, no. Ii, pp. 1296-1311, 2019.

[4] S. Sadi, "Prototype System Control Car Garage Based Microcontroller ATMEGA 8535," vol. 6, no. 4, pp. 91-108, 2015.

[5] C. N. Sumardi, Syamsul Bahri, "APLIKASI PENDETEKSI MANUSIA PADA TELEVISI BERBASIS MIKROKONTROLER ATMEGA8535,” J. Tek., vol. 5, no. 2, pp. 74-82, 2016.

[6] Sumardi Sadi, "Rancang Bangun Monitoring Ketinggian Air dan Sistem Kontrol pada Pintu Air Berbasis Arduino dan SMS Gateway," J. Tek., vol. 7, no. 1, pp. 77-91, 2018.

[7] A. Saefullah, S. Sadi, and Y. Bayana, "Smart Wheeled Robotic ( SWR ) Yang Mampu Menghindari Rintangan Secara Otomatis," vol. 2, no. 40, pp. 314-335, 2009.

[8] L. M. D. Pir, "Kontrol Pendingin Ruangan ( Fan ) dengan Logika Fuzzy Menggunakan Atmega 8535 ," vol. 2, no. 2, pp. 94-105, 2016.

[9] S. R. I. Mulyati, "INTERNET OF THINGS ( IoT ) PADA PROTOTIPE PENDETEKSI KEBOCORAN GAS BERBASIS MQ-2 dan SIM800L," vol. 7, no. 2, 2018.

[10] A. P. Hidayah and S. Sadi, "PENGATUR KESTABILAN SUHU PADA EGG INCUBATOR BERBASIS," J. Tek., vol. 6, no. 1, pp. 19-22, 2017.

[11] S. Sadi and Y. Mulya, "SISTEM KEAMANAN BUKA TUTUP KUNCI BRANKAS MENGGUNAKAN BLUETOOTH HC - 05 BERBASIS ARDUINO MEGA 2560," vol. 6, no. 2, pp. 99-105, 2017.

[12] S. Mulyati and Sumardi, "IoT on Door Security Control Prototypes based RFID and Bluetooth,” J. Tek., vol. 8, no. 1, pp. 11-16, 2019.

[13] S. H. Wisudo, W. Mawardi, and M. S. Baskoro, "Light Intensity PWM Design as a Tool to Attract Fish in Microcontroller-Based Stationary Lift Net," vol. 8, no. 03, pp. 75-82, 2019.

[14] S. H. Wisudo, W. Mawardi, and M. S. Baskoro, "THE IMPLEMENTATION OF THE RGB ON THE FISH BEHAVIOR IN THE LIFT-NET,” vol. 10, no. 3, pp. 352-360, 2019. 